\title{
A HISTÓRIA DO EUROCENTRISMO NA HISTÓRIA INTELECTUAL ${ }^{1}$
}

\author{
André Luan Nunes Macedo² \\ Doutorando em História \\ Universidade Federal de Ouro Preto \\ andreluanmacedo@outlook.com
}

\begin{abstract}
Resumo: O presente artigo procura realizar um balanço teórico e historiográfico sobre o conceito de eurocentrismo a partir de cinco perspectivas intelectuais de diferentes espaços geográficos e tempos: a crítica à Global History desenvolvida por Perla Pacheco; o pós-colonialismo indiano, representado pelos Subaltern Studies através de Dipesh Chakrabarty e Sanjay Seth, além dos formuladores do pensamento terceiro-mundista no contexto pós-colonial, como Robert Young; o decolonialismo latino-americano de Anibal Quijano e Enrique Dussel; e, por fim, os estudos vinculados à tradição marxista que aqui enquadramos no espectro das teorias do desenvolvimento/subdesenvolvimento propostas por Andre Gunder Frank e Samir Amin. O balanço das perspectivas intelectuais em questão tem como objetivo apontar suas semelhanças e contrastes. Tanto do ponto de vista teórico quanto metodológico, procurouse também observar os diferentes sentidos semânticos produzidos por tais intelectuais para o conceito em questão. Foi possível constatar duas correntes que produzem uma crítica ao eurocentrismo: uma com ênfase no aspecto cultural, vinculado às teorias do sujeito e dos "lugares de fala"; e a segunda, uma crítica holística ao eurocentrismo como fenômeno, pautada na análise macroscópica da história, tendo como objetivo ressignificar a ideia de globalidade e universalidade. Nesse sentido, o trabalho desenvolvido procurou traçar uma narrativa sobre a reflexão do conceito de eurocentrismo e seus diferentes usos ao longo do tempo.
\end{abstract}

Palavras-chave: eurocentrismo; Global History; decolonialismo; pós-colonialismo; teorias do desenvolvimento.

\section{THE HISTORY OF EUROCENTRISM IN INTELLECTUAL HISTORY}

Abstract: This article realizes a theoretical and historiographical balance on the concept of Eurocentrism throughout five intellectual perspectives from different geographical spaces and temporalities: the critique on the Global History developed by Perla Pacheco; Indian Postcolonialism, represented by Subaltern Studies and authors Dipesh Chakrabarty and Sanjay Seth, in addition the proponents of Third World thinking in postcolonial context, such as Robert Young; Latin-American Decolonialism of Anibal Quijano, Enrique Dussel; and, thus, the studies related to Marxist tradition framed as the Theories of Development/ Underdevelopment proposed by Andre Gunder Frank and Samir Amin. The balance of these intellectual perspectives has as main goal to point out its similarities and contrasts. Either on theoretical and methodological points of view, we observed the different semantic senses produced by these intellectuals for the concept. It was possible to note two different paths that produced a critique on Eurocentrism: an emphasis on the cultural aspect, linked with the theories of the subject and the "place of speech"; and the second, a holistic critique on Eurocentrism as a phenomenon, based on a macroscopic view of history, which aimed to re-signify the idea of globalism and universality. In this sense, this work tried to trace a narrative on the reflections about the concept of Eurocentrism and its different uses throughout the time.

Keywords: Eurocentrism; Global History; Decolonialism; Postcolonialism; Theories of Development.

\footnotetext{
${ }^{1}$ Texto recebido em: 17/12/2019; Texto aprovado em: 07/06/2020.

${ }^{2}$ Pesquisador Visitante no Centre for Postcolonial Studies - Goldsmiths, University of London/University of Wisconsin-Madison. Trabalho financiado pelo Programa de Doutorado Sanduíche da CAPES.

Currículo Lattes: http://lattes.cnpq.br/8508763929516597. ORCID: https://orcid.org/0000-0002-2968-2039.
}

Revista de Teoria da História - Volume 23, Número DI, Jul. de 2020

Universidade Federal de Gaiás - ISSN: 2175 - 5892 


\section{Introdução}

O presente artigo procura realizar um balanço teórico e historiográfico sobre o conceito de eurocentrismo. Ele é parte do nosso programa de pesquisa no doutorado que busca compreender a relação entre os conceitos advindos da experiência europeia e a construção da nacionalidade brasileira, em especial no ensino de história.

A dificuldade implícita na operação historiográfica em questão está, justamente, na escolha dos autores e na vasta produção sobre o tema. Qualquer tentativa como a que propomos fazer está condicionada ao desconhecimento de determinados autores e ao silenciamento não intencional de intelectuais que não fazem parte do balanço proposto. Por outro lado, viu-se a necessidade de uma apresentação mínima sobre o conceito, utilizado em larga escala e sem, contudo, contribuições que apresentem as diferentes formas de problematização do eurocentrismo em suas mais variadas vertentes. Nesse sentido, nosso intuito é de apresentar um panorama inicial sobre o tema, que não se esgota na construção deste artigo. Pelo contrário, propomos o levantamento para promover o debate, de forma que possamos, futuramente, incluir novas contribuições e preencher lacunas a respeito do conceito.

Fazemos o balanço a partir de cinco escolas intelectuais. Em um primeiro momento, parto dos pressupostos basilares contidos no campo intelectual da Global History e da historiografia latino-americana emergente. Tento compreender a crítica ao universalismo europeu como única forma possível e provável de análise holística da realidade. Parto aqui dos estudos da professora Perla Pacheco e sua "Nova História Global não eurocêntrica". Sua tese edifica um balanço histórico necessário para a história intelectual do conceito de eurocentrismo.

Partindo de um balanço historiográfico prévio, nossa intenção em um segundo momento é adentrar algumas definições sobre o conceito, tendo como objetivo alcançar os significados múltiplos assumidos pelos intelectuais distintos situados no campo "terceiro-mundista". Para realizar esse debate sobre os efeitos do eurocentrismo na história, é importante situar os estudos dos autores Pós-Coloniais. Nesse sentido, reivindico o estudo dos historiadores indianos Dipesh Chakrabarty e Sanjay Seth.

Nesses autores se percebe uma busca, no campo da história intelectual, da práxis do pensamento europeu no terceiro mundo. Quanto a Chakrabarty, coloco sua contribuição a respeito da provincialização da Europa em uma perspectiva global. Seu ensaio Provincializing Europe tem por objetivo caracterizar uma dialética própria do pensamento europeu quando 
materializado em outros continentes, considerado por Chakrabarty como um tipo de práxis cultural "inadequada e necessária ao mesmo tempo". Em Sanjay Seth, recorro às suas reflexões que buscam relativizar a epistemologia ocidental-iluminista advinda do pensamento eurocêntrico no que diz respeito à história e a exclusão de sujeitos não-ocidentais na produção da razão historiográfica. Para alcançar minimamente minhas pretensões, procuro trazer à baila da história intelectual dois outros campos específicos, originários da América Latina e África: o campo da Teoria do Desenvolvimento e o Decolonialismo.

O pensamento do historiador germano-estadunidense André Gunder Frank, pode-se dizer, é um alicerce dos estudos sobre a dependência latino-americana. Sua obra é pouco conhecida no Brasil, mesmo tendo o autor visitado estas terras, convidado por Darcy Ribeiro a compor a primeira geração de docentes da Universidade de Brasília e sido inspiração para intelectuais famosos da Teoria da Dependência, como Fernando Henrique Cardoso e Ruy Mauro Marini. Dentre os diversos ensaios produzidos por Frank escolhi a obra publicada em 1998, ReOrient: Global Economy in the Asian Age. Nesse trabalho, Gunder Frank faz uma crítica às correntes eurocêntricas de pensamento, não poupando críticas ao universalismo de Marx, Weber, Wallerstein, dentre outros. Como crítica ao eurocentrismo, propõe uma escrita da história "Globalcêntrica". Sua visão parte de uma teoria que situa a história mundial como uma movimentação entre civilizações centrais e periféricas.

Outro autor envolvido teoricamente com o pensamento marxista e de suma importância para a crítica ao universalismo europeu é o egípcio Samir Amin. Sua obra Eurocentrismo: crítica de uma ideologia é, pelo título, autoexplicativa no que diz respeito a sua centralidade quanto ao balanço historiográfico-intelectual que pretendo fazer. Além de oferecer um contraste quanto às pressuposições de Gunder Frank, Amin resgata as teses do capitalismo como um sistema que se produz a partir de bases desiguais e combinadas. Diante do cenário histórico sócio-econômico proposto pelo autor, o eurocentrismo seria, enquanto uma visão de mundo advinda das nações centrais, uma ideologia cultural, uma espécie de "amálgama" que estabelece o pano de fundo para a concretização das relações globais de poder entendidas, numa esfera geopolítica, entre o binário e abstrato West versus the Rest.

Nos mesmos anos 1960 na América Latina, os debates em torno da história do continente como uma história de reconfiguração da dependência e das assimetrias nas relações entre as nações centrais e periféricas são também edificados por intelectuais ligados ao 
pensamento decolonial. A dependência - entendida aqui também como um fenômeno histórico de perpetuação do colonialismo cultural - é um tema central para esses autores. Nesse sentido, o conceito de eurocentrismo é o ponto de partida para a reflexão desse campo intelectual. Procuro analisar os estudos de Enrique Dussel e Aníbal Quijano.

No primeiro autor, quero entender sua oposição à já criticada ideia de descobrimento da América. Ideia essa que é, atualmente, do ponto de vista da história intelectual, e que, traduzida a um velho ditado popular brasileiro, um "bater em cachorro morto". No entanto, a polissemia crítica ao conceito de descobrimento é um dos meus objetivos neste artigo. Acredito que Dussel elucida o eurocentrismo como um elemento da razão iluminista. Ao contrário de se gerar um pensamento translúcido e solar para o mundo, a razão do Velho Mundo procurou criar, a partir de um universalismo com pressupostos civilizatórios europeus, um encobrimento das outras formas de experiência societárias - dos povos originários americanos, africanos e asiáticos. Em Quijano, resgato suas reflexões epistemológicas contidas no seu artigo Colonialidad del poder, Eurocentrismo y América Latina.

\section{A Global History: entre o holismo e um "novo centrismo" geopolítico}

Pode-se afirmar que a Global History tem como marco o fim do século XX. O fim de uma polarização do mundo com a queda da União Soviética colocou a escrita da história em uma berlinda, uma vez que um dos grandes futuros produzidos pela ação humana - o socialismo - recebeu um forte golpe. Reivindicou-se o fim da União Soviética como um "fim da história". Essa foi uma das maiores "profecias" divulgadas, tendo como porta-voz Francis Fukuyama. Um bradar intelectual com forte conotação ideológica. Concomitante à crise do regime moderno de historicidade - conforme assinalado por François Hartog (2009) - surge o fenômeno da globalização.

Entender o que significa a globalização. Essa seria a premissa dos estudos iniciais da Global History com a predominância de estudos realizados nos Estados Unidos. A maior parte dos intelectuais que compõem o corpo de pesquisadores da área são estadunidenses. O lugar de fala dos autores e sua busca por uma história global que estabelecesse "novas dimensões" quanto às perspectivas historiográficas tem sido uma das principais críticas ao campo intelectual da Global History (2017). 
Perla Pacheco apresenta uma extensão temporal desse conceito para superar uma possível desconsideração com as diversas literaturas historiográficas que situam o holismo como categoria fundamental. Para isso, resgata Marx e Hegel como precursores de uma história total, tendo como objetivo uma escrita da história com um sentido próprio, ou, utilizando-se do termo comumente utilizado por ambos, "universal".

A universalidade proposta por esses autores tem passado por um largo crivo crítico, principalmente das correntes historiográficas que pretendo analisar nesse artigo. A Global History se encaixa como uma das mais recentes vertentes intelectuais críticas, uma vez que tem consigo a busca pela quebra do eurocentrismo. Pode-se dizer que uma história dita global parte, portanto, de duas premissas conceituais a serem formuladas: suas noções sobre o que é ser eurocêntrico e as origens da globalização (PACHECO, 2017).

Entender o conceito de globalização prescinde de um quadro histórico de longa duração no campo da história econômica e social. Como no filme De Volta para o Futuro se trata de ativar o "Delorean historiográfico" e retornar 500 anos na história, mais precisamente ao período da conquista da Abya Yala - como era chamada a América do Sul pelos Incas - ou, na visão do conquistador, o continente que será mais conhecido como América. O marco da conquista é também o marco da consolidação de um mercado mundial. Tanto na acumulação primitiva de capital de Marx quanto para o sistema-mundo proposto por Wallerstein, a gênese de uma interdependência transnacional se inicia no período citado:

La globalización, es un slogan y no una realidad nueva como afirma Immanuel Wallerstein, se tornó una palabra de uso obligado en la academia a pesar de que el término, en realidad, remite a una explicación del sentido común: la observación del incremento de la comunicación e interdependencia transnacional como correlato de la consolidación de una economía sin fronteras que había convertido al mundo en un solo mercado y que anunciaba la supuesta muerte de los estados nacionales, la cual nunca ocurrió (PACHECO, 2017, p.146-147).

A globalização, entendida como um fenômeno a ser consolidado entre o fim do século XX e início do século XXI, pode ser caracterizada a partir de duas dimensões específicas: por um lado, de encurtamento territorial, permitindo uma maior integração entre diversas civilizações e culturas, dada a aceleração da comunicação humana, estimulada pelo mundo high tech da internet, da alta programação e da interação virtual com mundos antes só tocados com a presença corpórea. Hoje, se quero entender o Japão e ver algumas dimensões paisagísticas daquele país, basta acessar o Google - nosso Oráculo Moderno - e, em um esforço gigantesco 
de 0,00001 segundos, tenho uma riqueza detalhada de informações. Sem dúvidas, para o historiador intelectual e aqueles envolvidos com a história dos conceitos, a internet é um sonho de consumo. O mundo "nanotecnologizou-se".

Se por um lado a informação total da produção humana cabe em uma tela de um computador, o mundo globalizado produz, com a padronização e a virtualidade, uma homogeneidade. Nas palavras do professor Gilberto Felisberto Vasconcellos, vivemos a era do Capitalismo Vídeo-Financeiro (2014). A tecnologia assume o fetiche de "motor da história" e é ela quem demarca as eras do empreendimento humano existencial. A busca por uma homogeneidade quanto à técnica tem seu amálgama o cinema e outros meios de produção cultural de massas. Em um de seus ensaios, o autor descreve com uma acidez pertinente a busca incessante pelo domínio de técnica, principalmente representada pelo cinema "roliudiano" e pelo campo acadêmico:

\begin{abstract}
A tecnologia tornou-se a palavra-chave nos pronunciamentos de todos os líderes burgueses, assim como é peça fundamental no léxico dos acadêmicos, tanto em sociedades avançadas quanto nas subdesenvolvidas. É impressionante nas últimas décadas como a tecnologia (computador e telefone celular) desempenha papel protagônico no cinema roliudiano. É a destreza do uso do computador e do celular que decide a sorte do bandido e do mocinho, mas não apenas nos filmes do cinema dominante encontra-se o enaltecimento da democracia eletrônica, da sociedade da informática, da cidadania online e do telepluralismo. Assim, Bill Gates está in; Lenin out; a internet é aplaudida por trazer a 'igualdade virtual'. É sempre pelo ângulo do processo de desenvolvimento tecnológico (agora o determinismo microchip) que se reconhece o triunfalismo capitalista com as mirabolantes periodizações da história em 'modernidade' e 'pós-modernidade' (VASCONCELLOS, 2014, p. 110-111).
\end{abstract}

O fetiche da tecnologia tem consigo um pressuposto metafísico, ou seja, que prescinde a ação humana e seus antagonismos. A dimensão cultural do mundo global incute um desejo contrário de busca incessante pelas diferenças, por mais que integrada e homogeneizante a partir deste agir nanotecnologizado. $\mathrm{O}$ antagonismo deste mundo globalizado convive (harmoniosamente?) com o multiculturalismo. Por mais que o mundo seja entendido como uno, conforme quer o discurso vídeo-capitalista dominante, a outra faceta discursiva da mesma moeda sistêmica atual é o elogio de corte liberal à diferença. Nesse mundo territorial chamado Terra existem mundos, tempos e histórias distintos entre si:

Esta preocupación por la diferencia cultural no surgió por generación espontánea en los años noventa, sino que se hizo sentir décadas antes a inicios de la posmodernidad desde los años sesenta bajo un contexto de apogeo del relativismo, el 
multiculturalismo, las reivindicaciones étnicas dentro de Europa y las luchas de descolonización en Asia y África que araron terreno fértil para la convergencia de las discusiones en torno al multiculturalismo y la globalización. Esta convergencia trajo un ímpetu por estudiar la conformación histórica de sociedades no occidentales interconectadas en una economía global, interés que comenzó a delinearse como una nueva forma de abordaje historiográfico que pasaría a ser conocido como historia global. Este giro global multicultural impactó con fuerza fuera y dentro de la academia, lo que resultó en un lenguaje muy cercano a las teorías poscoloniales que hablaba de mundos, tiempos e historias en plural frente al discurso homogeneizador de una rancia historia universal como relato ciego y sordo hacia las diferencias culturales (PACHECO, 2017, p.148-149).

Os debates em torno do multiculturalismo e da Global History possuem um denominador nacional em comum: os Estados Unidos. A americanização das ciências sociais com uma escola própria de pensamento tem gerado, em alguns casos, divergências quando expostas a intelectuais de longa tradição acadêmica no ocidente, principalmente espanhóis e franceses (PACHECO, 2017, p.148-149). A busca por uma heterogeneidade contida na visão de mundo da escola anglo-saxã tinha como objetivo contrapor-se a uma história universal "cega e surda ante as diferenças culturais" (PACHECO, 2017, p.150 - tradução nossa).

Como toda historiografia ou, pode-se dizer, escola acadêmica, a sua comunidade de origem/destino demarca uma práxis intelectual condicionada aos interesses nacionais. Nesse sentido, a nação não limita por si mesma a prática científico-metodológica do holismo. No entanto, o seu lugar de fala não é despretensioso ou desinteressado. Não há espaço, portanto, para um "cosmopolitismo abstrato". Esse é o alerta da professora Pacheco no que diz respeito à história global anglo-saxã. Quando se reivindica um "olhar mais plural do mundo e da periferia", há implicitamente, uma historiografia interessada do ponto de vista geopolítico:

\begin{abstract}
Al ser producto de las academias anglosajonas la nueva historia global ha mostrado un marcado interés por las antiguas colonias y espacios de intervención política y económica de Estados Unidos y Europa del norte, que hoy día se han desarrollado como economías claves para el mercado global. Es decir, existe un interés por analizar las relaciones principalmente económicas, aunque no exclusivamente, desarrolladas entre estos centros y sus periferias casi como una necesidad de la agenda política internacional de la sociedad global, no obstante solo algunas de estas periferias han sido privilegiadas por el análisis de los historiadores globales. Estas han sido China, India y Rusia que son casualmente los principales socios comerciales de las economías del primer mundo, aunque también se han enfocado en el estudio de otros espacios como Japón, el Pacífico y el mundo musulmán en Medio Oriente y África del norte. El interés de la nueva historia global por zonas específicas de Asia genera una asimetría en su producción historiográfica que comienza a equilibrarse, al aparecer, con cada vez más trabajos que incluyen al África subsahariana, América Latina y los propios márgenes dentro de Europa (PACHECO, 2017, p.151).
\end{abstract}

Revista de Tearia da História - Volume 23, Número DI, Jul. de 2020

Universidade Federal de Gaiás - ISSN: 2175 - 5892 
A promoção do jogo de escalas nação/região é de suma importância para a Global History. Mesmo que se tenha por princípio fugir da lógica comparativa, a história global anglófona assume as arestas das ditas comunidades de origem/destino, como quaisquer outras. Apesar disso, ao assumir um enfoque que tem por pressuposto a globalização, seus temas "clássicos" estão ligados a história das epidemias; o impacto da constituição estadunidense em diversas partes do mundo; ou de um produto econômico em particular, como o algodão, por exemplo (PACHECO, 2017, p. 151). Os temas, percebe-se, possuem consigo uma metodologia de observância própria, de cunho transnacional. A transversalidade da ideia nação-região perpassa a edificação do como fazer a Global History. Para além de dimensões econômicas, a Global History quer ser uma referência na inteligência de estudos estrategicamente importantes do ponto de vista geopolítico.

É interessante questionar o "lugar social" dessa historiografia emergente, calcada em condicionamentos e imposições no ato da escrita da história. Segundo Certeau, o lugar social da escrita da história " delineia uma topografia de interesses, que os documentos e as questões, que lhes serão propostas, se organizam" (CERTEAU, 1982, p. 56). Tais “questões”, ou seja, os recortes históricos, são constantemente condicionados pelos interesses das comunidades de destino, não havendo espaço, portanto, para a despretensão ou o internacionalismo abstrato.

Ao mesmo tempo, lembrar a centralidade do objeto de reflexão desse artigo: afinal, se a escola historiográfica em análise busca romper com uma universalidade "surda e cega ante as diferenças culturais" - leia-se: eurocêntrica - não estaria ela propondo criar um novo recentramento historiográfico, que situe os Estados Unidos como um "Farol de Alexandria" intelectual, dado sua posição hegemônica de alto poderio global? Estaríamos diante de um "novo centrismo"? A comunidade de origem/destino da Global History inviabiliza, portanto, sua pretensão de globalidade? Pacheco fornece algumas pistas para compreender um sentido do ser eurocêntrico:

La nueva historia global se abre a las historias no occidentales para construir un relato plural e incluyente, pero esto no desaparece sus propios prejuicios eurocéntricos, pues no podemos pensar que el eurocentrismo es solo una forma de ver mundo, es la expresión de las relaciones globales de poder que son muy reales [...]La nueva historia global no tiene concepto de eurocentrismo ni una epistemología ni un método para afrontarlo, se conforma con la pura dilatación del obturador de la escala, de manera que pareciera ser que para escribir historia global hoy día basta con alinearse con lo políticamente correcto que es incluir en el relato a los espacios no occidentales sin ofrecer necesariamente una interpretación curada de eurocentrismo. Los propios historiadores globales como Bruce Mazlish confiesan que si bien el enfoque 'todavía 
se ve lastrado por un eurocentrismo inconfeso, ha realizado avances significativos en el proceso de liberarse de ese punto de partida'. Es decir, que ya no parten de Europa como único sujeto de la historia, pero siguen interpretando la historia con paradigmas europeos, una historia que ahora es interconectada y transnacional (PACHECO, 2017, p. 159-160) [grifos meus].

Superar o paradigma eurocêntrico. Essa parece ser uma das mais importantes obsessões da chamada Global History. As dificuldades de fugir das metodologias predominantes nos colocam em uma berlinda: relativizar o paradigma europeu e detectar um amálgama ideológico sem que, com isso, se consiga uma proposição historiográfica que o supere não é produzir um tom excessivamente criticista e, em larga medida, obscurantista sobre a história da ciência e a história intelectual? Ou, partindo do pressuposto das limitações quanto as relações de poder, demarcadas pela questão nacional, haveria alguma outra tendência intelectual capaz de fornecer uma história não-eurocêntrica, ou, em alguma medida, não-etnocêntrica?

\section{Provincializar a Europa: o Pós-Colonialismo e os labirintos da identidade terceiro- mundista}

As questões levantadas trazem uma dimensão antropológica sobre a produção do discurso histórico. Trata-se de edificar um pensamento abstrato o suficiente para que seja possível consolidar uma universalidade quanto ao devir temporal. As rotas e encruzilhadas do nosso percurso intelectual questionam frontalmente os caminhos oferecidos pelo pensamento europeu como solução para a interpretação da (s) história (s) do (e no) Terceiro Mundo. No entanto, é possível fabricar um discurso histórico sem que conjuremos uma "caixa de ferramentas" metodológica e teórica oferecida pela tradição ilustrada? Afinal, a história como ciência e formulada enquanto tal não é uma produção europeia e ocidental? É possível fazer uma história que parta de pressupostos objetivos que neguem o "Velho Mundo"?

Parafraseando Leonel Brizola, para responder tais questões, nosso percurso precisa “navegar em águas mais profundas, ir para além da espuma do mar”. Ou seja, é necessário sair da encruzilhada dos caminhos simplórios e binários muitas vezes oferecidas por vertentes de pensamento relativistas/pós-modernas. É preciso ir para além de uma historiografia negacionista advinda das periferias, caracterizada por Leela Gandhi (apud. CHAKRABARTY, 2015, p.16) como uma espécie de vingança pós-colonial. 
A chave para a saída do relativismo é problematizada por Dipesh Chakrabarty em sua obra Provincializing Europe: Postcolonial Thought and Historical Difference, segundo a qual o europeu se situa a partir de uma dialética entre materializar uma razão "historicamente indispensável e, ao mesmo tempo, inadequada" para os povos do Terceiro Mundo (CHAKRABARTY, 2015, p.16). No campo da práxis, tal dialética é perceptível a partir do seguinte modus operandi intelectual:

Por gerações em diante, filósofos e pensadores que modelam a natureza da ciência social produziram teorias que abarcam a totalidade da humanidade. Como bem sabemos, essas afirmações foram produzidas numa relativa e muitas vezes absoluta, ignorância da maioria da humanidade - ou seja, daqueles que vivem em culturas não-Ocidentais. Isso por si não é paradoxal, por mais auto consciente que os filósofos europeus buscaram justificar teoricamente essa posição. O paradoxo cotidiano de uma ciência social do terceiro mundo é que nós encontramos essas teorias, apesar das suas ignorâncias inerentes do "nós", eminentemente úteis para compreender nossas sociedades. O que permitiu os sábios europeus modernos em desenvolver tamanha clarividência com relação a sociedades nas quais eram empiricamente ignorantes? Por que nós, mais uma vez, retornamos o olhar? (CHAKRABARTY, 2015, p. 29 tradução nossa).

O modus operandi denunciado por Chakrabarty é visível não somente no continente asiático. A crítica ao pensamento eurocêntrico, segundo o autor, assume uma pluralidade que demarca a complexidade da crítica ao "universalismo cego e surdo diante das diferenças históricas" resultantes dos pós-colonialismos latino-americano, asiático e africano.

Partindo de uma outra matriz teórica (o marxismo latino-americano ou a chamada Teoria Marxista da Dependência), o professor Nildo Ouriques estabelece uma crítica semelhante à práxis intelectual dominante nas universidades brasileiras, preconceituosa com os "filósofos de sua aldeia". Para Ouriques, Álvaro Vieira Pinto não é lido devido a esse cosmopolitismo abstrato. Suas ideias são semelhantes ao projeto de provincialização da Europa no terceiro mundo proposto como tese por Chakrabarty. $\mathrm{O}$ que diferencia o indiano do economista brasileiro seja, talvez, o alto grau de acidez retórica proposta pelo segundo:

As publicações recentes de Álvaro Vieira Pinto romperam de uma vez por todas com a máxima colonial popularizada pelo cantor Caetano Veloso segundo o qual 'está provado, só é possível filosofar em alemão', peça do eurocentrismo e do colonialismo cantada com simpatia pela juventude embalada no ensino filosófico alienante que predomina entre nós (OURIQUES, 2015, p.33).

A fala pretensiosa do universalismo europeu consolida incongruências empíricas relacionadas aos saberes específicos deste Terceiro Mundo. A concentração da autoridade das 
ciências sociais promoveu a imposição do ser europeu nas culturas não-ocidentais. Só se é filósofo dotado com o mínimo de autoridade se o for mediante a "complexa" língua alemã. Para ser sociólogo de renome, é preciso afrancesar seu trabalho. Recentemente, uma pitada anglosaxã (seja estadunidense ou inglesa) garante discursivamente uma autoridade ao trabalho na área das humanidades. Porém, negar a autoridade desses campos intelectuais irá nos permitir fazer uma história intelectual ou uma teoria da história mais próxima à realidade latinoamericana e periférica? Não necessariamente. Aliás, para Chakrabarty a própria representação do ser "indiano", "chinês" ou "terceiro mundista" aparecem como variações complementares do ser analítico europeu, "indeterminada e hiper-realista" quanto às suas definições históricotemporais:

É isso na medida em que o discurso acadêmico da história - isto é, 'história", como um discurso produzido no lugar institucional da universidade - está preocupado, a 'Europa" mantém a soberania do sujeito teórico de todas as histórias, incluindo aquelas que chamamos de 'indiana', 'chinesa', 'queniana' e assim por diante. Existe uma maneira particular em que todas essas outras histórias tendem a se tornar variações de uma narrativa majoritária que poderia ser chamada de 'história da Europa'. Nesse sentido, 'a história indiana' por si mesma está numa posição de subalternidade [...] 'Europa' e 'Índia' são tratados aqui como termos hiper-reais referentes a certas figurações imaginativas cujos referentes geográficos permanecem de alguma forma indeterminados. Como figuras do imaginário elas são, obviamente, sujeitas a contestação, mas para o momento tratarei delas da forma como foram dadas, categorias reificadas, opostos emparelhados numa estrutura de dominação e subordinação (CHAKRABARTY, 2015, p.28 - tradução nossa).

Se dialogássemos por um instante com os tipos ideais de sentido histórico formulados pelo professor alemão Jörn Rüsen para explicar o raciocínio dialético de Chakrabarty, construir uma narrativa que explique o fenômeno de provincialização da Europa não perpassa necessariamente pela produção de uma contranarrativa de representação "pura", única e exclusivamente dos "debaixo" e "terceiro-mundista". Mesmo que a intenção seja criar uma narrativa do subalterno que apresente sua pluralidade de mundo, a razão ocidental também condicionou por séculos toda uma cultura histórica sobre o ser indiano, brasileiro, argentino, venezuelano, latino-americano etc.

Não se pode negar, por exemplo, a importância da história do Partido Comunista para a questão da luta pela descolonização da África e Ásia, por exemplo. Por mais que muitas de suas interpretações temporais oferecessem modelagens ideativas e imprecisas sobre as formações históricas, o Partido Comunista foi uma importante célula intelectual em grande parte das 
periferias do mundo. Segundo Hobsbawm, a ideia do Partido Comunista é uma das maiores engenharias sociais já criadas pela humanidade, comparável à criação das ordens cristãs no período medieval (HOBSBAWM, 1994, p.76). Nesse sentido, o historicismo ocidentalmarxista possui determinada peculiaridade. Mesmo que inadequado em termos de formulação histórica, certo marxismo foi - e ainda é - um instrumento ideativo e prático para agir e promover a libertação dos subalternos. Não somente o marxismo, como a práxis intelectual da tradição iluminista foi componente importante para a produção de uma linguagem de rebeldia. Conforme proposto por Arif Dirlik (1999), a relação entre o colonizador e o colonizado produziu importantes "zonas de contato", ou seja, traduções de pensamento e práticas de superação do antagonismo imposto pelo poder eurocêntrico do conhecimento.

É dessa zona de contato que se produz os novos nacionalismos e a luta pela descolonização Tricontinental. Segundo Robert Young (2001), é o forjar de pensamentos independentistas que cria as condições para o nascimento das teorias pós-coloniais. Diferentemente do nacionalismo de cunho provinciano, o pensamento Tricontinental contribuiu para entender as especificidades das lutas de libertação nacional e, com isso, produziu uma estratégia de sincronização e interdependência destas lutas. Um dos movimentos mais importantes para a consolidação do pós-colonialismo foi a reunião dos Países Não-Alinhados e a Organização de Solidariedade com os Povos de Ásia, África e América Latina (OSPAAAL). Segundo Young o pós-colonialismo é uma variante do pensamento Tricontinental:

\begin{abstract}
Mais radicalmente, pós-colonialismo - no qual prefiro chamar tricontinentalismodenomina uma posição política e teórica que incorpora um conceito ativo de intervenção dentro de circunstâncias opressivas. Combina as invocações epistemológico-culturais do momento pós colonial com a crítica política das condições da pós-colonialidade, Nesse sentido, o 'pós' do pós-colonialismo, ou crítica pós-colonial, demarca o momento histórico de introdução teórica das novas formas e estratégias tricontinentais de análise crítica e prática. Diferentemente das palavras 'colonialismo', 'imperialismo e 'neocolonialismo', adotadas somente para a relação crítica com os regimes e práticas que elas delimitam, o pós-colonialismo é tanto contestatório e comprometido com ideais políticos de uma justiça social transnacional. [...] Pós-colonialismo portanto designa a perspectiva das teorias tricontinentais que analisam as condições materiais e epistemológicas da pós-colonialidade e visa combater o sistema imperialista de dominação econômica, política e cultural, mesmo que coberto (YOUNG, 2001, p.58 - tradução nossa).
\end{abstract}

Os anos 1950 e 1960 foram períodos importantes para o amadurecimento da crítica ao colonialismo e a formação de novos pensamentos nacionais. De políticos como Jawaharlal Neru, Mao Tse Tung, Ho Chi Minh, Fidel Castro, passando por intelectuais dos países centrais 
e periféricos - Frantz Fanon, Aimé Césaire e Jean Paul Sartre - todos deram sua contribuição para a luta contra o colonialismo, oferecendo novas bases epistemológicas, políticas e culturais.

Não se pode negar que o diálogo com determinadas especificidades periféricas fez com que um determinado tipo de razão historicista ocidental apresentasse visões equivocadas sobre a realidade das periferias. De todos os dogmatismos a serem revistos pelo campo, cito a análise do caso indiano feita por Marx como um de seus maiores equívocos. Até mesmo o império britânico transforma-se em um motor progressista da civilização ao exercer seu domínio, podendo quebrar com a arquitetura do poderio das castas na Índia (MARX, 1981, p. 21-24), uma vez que o camponês indiano passaria a se organizar coletivamente nas fábricas de tecidos, gerando assim, por motivos de organização econômica, uma consciência de classe efetivamente revolucionária. Por mais que houvesse um processo duro de violência e aculturação do camponês tecelão indiano, essa seria a única alternativa historicamente viável para que tivesse condições objetivas de emancipação radical. Segundo o historiador argentino Jorge A. Ramos:

\begin{abstract}
El ferrocarril británico en la India, como lo hizo en la América Latina, no llevó sin embargo a la creación de la industria hindú, sino a la destrucción de las viejas artesanías nacionales y a la introducción de los productos terminados de la industria inglesa. Las castas hindúes, no sólo no fueron suprimidas, sino que por el contrario fueron fortalecidas por el conquistador y subsisten hasta hoy, como resultado del apoyo inglés a los príncipes y déspotas orientales. En ese orden de las ideas, las previsiones de Marx no se han verificado (RAMOS, 2012, p.376).
\end{abstract}

Passados mais de 160 anos, percebemos que o motor da história britânico mais incorporou os atrasos da arquitetura casta indiana que necessariamente rompeu com ela. Também não podemos exigir uma explanação metafísica de Marx sobre os problemas da humanidade, afinal de contas, o capitalismo desenvolvido no século XIX e o capitalismo dos séculos posteriores passaram por consideráveis transformações históricas. Dialogando com Darcy Ribeiro (1979), o processo de atualização histórica dos séculos XX e XXI inaugura uma nova etapa do capitalismo, também entendida pela concepção econômico-ideológica da reinvenção do colonialismo, o neocolonialismo.

Diante da inflexão historicista promovida por certa práxis advinda de um marxismo digamos, puramente economista, qual é a saída para consolidar uma história intelectual nãoeurocêntrica e que, ao mesmo tempo, não caia nas armadilhas do relativismo culturalista de verniz pós-moderno? Ainda no campo dos estudos pós-coloniais existem alternativas para a 
saída dessa crise histórica, mesmo se utilizando de uma perspectiva que relativize a razão histórica ocidental.

Segundo o professor indiano Sanjay Seth, a história enquanto instrumento científicoprático da razão ocidental gerou um tipo de aplicação, por vezes paroquial, de determinada universalidade não existente em civilizações e culturas ditas não-ocidentais. A inflexão deste tipo de historicismo trabalha com a marginalização dos chamados passados não-ocidentais, "incapazes" de ser história. Dentre eles, o autor cita o selvagem, a mulher e o oriental como sujeitos marginalizados desta universalidade historicista. Em contraponto ao historicismo, Seth defende a história como uma interseção de diferentes tradições de raciocínio:

\begin{abstract}
Chamemos de Razão a esse complexo conjunto de atitudes, ou, mais precisamente, ao comprometimento com uma ideia ou com uma Razão que seja singular e universal. Notemos que, apesar de essa Razão não ter sido destronada, sob as investidas combinadas porém variegadas do feminismo, da teoria queer, do pós-modernismo, do pós-colonialismo e de outras correntes intelectuais, ela está (para mudar as metáforas), de fato, cambaleando sobre o seu pedestal. Mas a natureza dos desafios suscitados por essas correntes e os movimentos que frequentemente propiciaram as condições para que elas pudessem emergir são duas coisas distintas. É um importante argumento (ainda que, na atualidade, já seja um lugar-comum) que a própria ideia de Razão se constituiu, em parte, por meio de uma série de exclusões - da loucura, das mulheres, e assim por diante. Uma estratégia para problematizar a Razão é, portanto, a de demonstrar as contingências e as exclusões adotadas na sua criação (SETH, 2013, p.174).
\end{abstract}

Entendida como um código, a história não pode, ao conceber e construir seu objeto de estudo, desconsiderar determinadas visões cosmogônicas para a construção do passado, por exemplo. Pode-se dizer que a inclusão de uma pluralidade de tradições do passado abre a possibilidade, segundo Seth, de sair de uma certa ingenuidade epistemológica, cujo princípio se baseia num espontaneísmo do "acontecer histórico", fruto de uma demarcação temporaluniversal antes não questionada. Afinal:

O passado não está para sempre disponível ao presente como uma entidade emudecida, esperando que o (a) historiador (a) lhe dê uma voz. A escrita da história não é simplesmente um "ofício" que se aplica a um objeto pré-existente, natural; ao contrário, e como qualquer disciplina, a escrita da história concebe e constrói o seu objeto (SETH, 2013, p.180).

Partindo desse pressuposto, a escrita da história possui uma dimensão construtivista. Não há, nesse tipo de raciocínio, o real como uma dimensão espontânea e explicada 
intrinsecamente por si mesma. Assumindo a caracterização da razão histórica proposta por Claude Lévi-Strauss, a historiografia funciona a partir de uma organização, estabelecida por um código que classifica as datas (apud SETH, 2013, p.180). Essa organicidade historiográfica prévia pressupõe ações e imposições que encobrem outros tipos de tradição sobre a consciência histórica e a relação com os passados.

Mesmo com o esforço de pluralidade, ainda vejo que, ao explicar as diferentes tradições de raciocínio, o pensamento de Seth pode ser ainda levado, se mal interpretado, a um sentido histórico contra-narrativo ao pensamento ocidental. Afinal, como sair dessa inflexão epistêmica? O autor nos oferece uma interessante síntese:

É claro, isso não significa dizer que devemos deixar de escrever histórias da Índia. Não estou propondo aqui que os historiadores abracem uma determinação autoanuladora. E menos ainda que abandonemos a argumentação e o exercício da crítica. Pluralizar a razão não significa abandonar o raciocínio; negar que existe um ponto arquimédico, a partir do qual é possível exercer a crítica, não é defender o fim da crítica. Mas é, sim, defender uma reconsideração daquilo que pensamos estar fazendo quando redescrevemos o(s) passado(s) dos povos em termos que lhes são alheios. Se o que existe é não a Razão, e sim tradições de raciocínio; não a História e suas representações na escrita da história, e sim muitos passados re-presentados de muitas formas, então não podemos escrever com qualquer presunção de privilégio epistêmico. Precisamos conceber a escrita da história do modo ocidental e moderno não com um veio imperialista (não estamos corrigindo as percepções errôneas dos outros acerca dos seus passados), e sim como um exercício de tradução (estamos traduzindo as suas autodescrições em termos que fazem sentido dentro das nossas tradições intelectuais). Não se trata de recuar em nossas tradições - pois elas são o ponto de partida do nosso exercício de razão, se quisermos mesmo exercitar a razão. Só não atribuímos a elas um privilégio epistêmico a priori (SETH, 2013, p.187).

A resposta oferecida por Sanjay Seth não possui nenhum maniqueísmo analítico. Não parte de uma configuração histórica simplista, cujo princípio se dá a partir de uma oposição entre o Iluminismo historicista europeu e as chamadas tradições de passado não-ocidentais. A escrita da história é situada com amplitude e abstração necessárias para um raciocínio histórico potente e de síntese, na qual a pluralidade de visões sobre um mesmo fato construa novas relações subjetivas, sem que haja, portanto, um privilégio epistêmico a priori. Seth oferece uma visão cultural mais ampla da escrita da história. Ao pensar uma mediação cultural diversa, horizontal e transversal no que diz respeito às diferentes formas com que concebemos o passado, é possível se libertar de uma razão unívoca, que tem uma mônada discursiva constituída a partir do universalismo europeu. 


\section{O Decolonialismo, a Teoria do Desenvolvimento Global/Teoria da Dependência: divergências antagônicas?}

Entre os intelectuais que fazem parte do campo crítico-marxista e decolonial, os autores André Gunder Frank, Samir Amin, Enrique Dussel e Aníbal Quijano possuem algumas proximidades interessantes. Apesar de tanto Gunder Frank quanto Amin não reivindicarem uma filiação à Teoria da Dependência, ambos têm por objeto de estudo o sistema-mundo e as relações desiguais e combinadas oriundas do pensamento trotskista do ponto de vista econômico e sociológico na reprodução do mercado mundial. Por meio de uma combinação com uma visão historicista que busca conferir sentido à evolução das relações de produção, Frank e Amin apresentam evidências quanto ao desenvolvimento de aparatos científicostecnológicos de produção em outras partes do mundo, principalmente a partir do caso chinês.

Pode-se dizer que ambos também partem das relações entre centros e periferias, propondo uma Teoria do Desenvolvimento Global. Deve-se distinguir a proposta elencada pelos autores com a teoria desenvolvimentista elaborada por Raul Prebisch e Celso Furtado. O objeto de estudo de Gunder Frank parte de um questionamento dialético que não vê a possibilidade de alcance do desenvolvimento nas periferias, tendo como princípio o estudo da realidade europeia e estadunidense como modelo para a evolução das civilizações periféricas. Para Frank, o sistema-mundo, ao longo da história, reconfigurou as relações entre as civilizações consideradas centrais e seus satélites, gerando um desenvolvimento subordinado, ou, partindo de seu postulado mundialmente famoso, um desenvolvimento do subdesenvolvimento.

Existem duas trincheiras de combate teórico estabelecidas pelo historiador germanoestadunidense: a primeira busca refutar a tese essencialista de desenvolvimento herdada de uma tradição weberiana, cuja base de pensamento sobre o desenvolvimento social parte de um pressuposto endógeno (FRANK, 1998, p.28). O desenvolvimento econômico e histórico se daria, segundo tal vertente, a partir de um "processo evolutivo". Essa essência interna é o que daria a possibilidade de constituição de modelos científicos, ou, na linguagem weberiana, de tipos ideais a serem espelhados e reivindicados por outras nações/ civilizações que não tivessem incorporado os elementos ocidentais de racionalização burocrática e de "modernização" do Estado. 
O segundo front de enfrentamento de Gunder Frank estaria ligado a filosofia da história proposta por Marx, segundo a qual o motor da história da humanidade seria a luta de classes. Em contraposição a essa tese, sua perspectiva parte de uma nova filosofia da história: a divisão mundial do trabalho:

E a classe e as lutas de classes? Tragam o Estado de volta! Deem mais espaço para a cultura! Minhas respostas de forma curta são que existem classes na economia mundial, mas a luta entre classes dirigidas e dirigentes nunca foram a força motriz como Marx atribuía a elas - quando ele tirou fora seu chapéu materialista histórico. $\mathrm{O}$ Estado e a cultura e, portanto, a luta de classes em si, requerem muito mais análises como sendo elas mesmas dependentes em uma dinâmica e estrutura da economia mundial e seu sistema (FRANK, 1998, p.43 - tradução nossa).

Ao assumir uma metodologia advinda de macro-historiadores, Gunder Frank prefere o uso do telescópio para a interpretação do mundo e a geração de uma teoria social em detrimento de uma visão microscópica. Seu historicismo holístico tem como base uma historiografia pautada nas relações econômicas. Ao refutar a ideologia da globalização, Frank apresenta uma teoria social que defende a integração de um sistema-mundo já existente há mais de dois mil anos. Não haveria, portanto, nenhum indício de excepcionalidade europeia, cuja pressuposição seria a conquista de territórios e novos mercados a partir do século $\mathrm{XV}$, conforme sugerido pela "teoria eurocêntrica do sistema-mundo" de Immanuel Wallerstein.

Ao assumir o telescópio, pode-se dizer que Frank também caminha num sentido contrário às propostas sugeridas pelos historiadores pós-coloniais. Seu objeto de estudo não é constatar as diferenças históricas entre o europeu e os passados não-ocidentais. O autor parte de um raciocínio histórico, digamos, hegeliano, cujo pressuposto é a busca por uma explicação unitária do mundo. No entanto, caminhando num sentido contrário ao desenvolvimento histórico de vetor único-eurocêntrico e excepcionalista, Frank esclarece que o desenvolvimento industrial não é fruto de uma excepcionalidade europeia, e sim das complexas relações deste sistema-mundo:

O debate sobre 'interno versus externo' torna a análise baseada na Europa e seu 'sistema/ economia mundial moderna' em um outro obstáculo e resistência a ser superado. O argumento baseia-se também em algo 'interno' do 'sistema mundo moderno' europeu gerado pela transição do feudalismo para o capitalismo, que posteriormente se espalha para o resto do mundo 'de fora'. Afirmo que, pelo contrário, a Europa e sua 'economia mundial' foram parte e parcela de uma longa e pre existente economia Afro-Eurasiana cuja estrutura sistêmica própria tornou-se global - e por si gerou diversos desenvolvimentos na Europa; Portanto, é a operação 'interna' da 
economia do mundo global - e não somente da 'economia mundial' europeia - que demanda análise (FRANK, 1998, p. 42 - tradução nossa).

Pelo fato de se estar integrado em um sistema-mundo e ter sido, antes da conquista das américas, uma periferia econômica da China, a Europa alcançou condições objetivas diversas para a conclusão de sua revolução industrial, especialmente a Inglaterra, gerando, assim, "uma ascensão do Ocidente". Esta visão dialética é a base do pensamento gunderfrankiano, que enxerga uma unidade de contrários - pautada na produção de diversidades dentro de um mundo orientado por uma divisão internacional que ocasionou a relação entre economias centrais e periféricas.

As ideias de Gunder Frank serviram de inspiração para muitos intelectuais na América Latina. Para Felisberto Vasconcellos, suas ideias foram apropriadas por autores renomados como Florestan Fernandes, Darcy Ribeiro, Ruy Mauro Marini, Theotonio dos Santos, Fernando Henrique Cardoso, dentre outros.

As perspectivas de Frank e Amin possuem o esforço de situar a história universal para além dos preceitos colocados por, segundo Amin (1989, p. 10), uma "tradição culturalista helênica". O eurocentrismo se organiza, em termos de orientação prática, a partir de três momentos históricos-chave para a construção de uma narrativa tida como "universal": a) a reivindicação da autenticidade da Grécia Antiga enquanto formuladora de um projeto filosófico único e singular; b) a construção de uma ideia de Modernidade com o processo de conquista nas Américas, situando o "Novo Mundo" como continente subordinado e um importante elemento de alteridade para o ego europeu; e c) um desenvolvimentismo histórico de raiz hegeliana, no qual o europeu é vanguarda da construção de um universalismo que possui um vetor de orientação evolucionista, colocando a Europa como o centro cultural-civilizatório mais "maduro" da humanidade, inaugurando, assim, a dialética entre os "que possuem história" e os demais, ausentes de consolidarem uma experiência temporal complexa.

A partir desse pressuposto metodológico globalista, conforme sugerido por Gunder Frank, há nas perspectivas dos autores mencionados a crítica aos essencialismos e teleologias míticas criadas pela teoria eurocêntrica da história. Segundo Samir Amin:

El eurocentrismo es un culturalismo en el sentido de que supone la existencia de invariantes culturales que dan forma a los trayectos históricos de los diferentes pueblos, irreductibles entre si. Es entonces antiuniversalista porque no se interesa en descubrir eventuales leyes generales de la evolución humana. Pero se presenta como 
un universalismo en el sentido de que propone a todos la imitación del modelo occidental como única solución a los desafíos de nuestro tiempo. El eurocentrismo no es la suma de prejuicios, equivocaciones e ignorancias de los occidentales con respecto a los demás. Después de todo, éstos no son más graves que los prejuicios inversos de pueblos no europeos, para con los occidentales. No es pues un etnocentrismo banal, testimonio sólo de los limitados horizontes que ningún pueblo del planeta ha superado verdaderamente todavía. El eurocentrismo es un fenómeno específicamente moderno cuyas raíces no van más allá del Renacimiento y que se ha difundido en el siglo XIX. En ese sentido constituye una dimensión de la cultura y de la ideología del mundo capitalista moderno (AMIN, 1989, p.9).

Conforme apresentado no trecho acima, Amin abandona a perspectiva de enfrentamento do eurocentrismo como um fenômeno cultural, ligado a um simples silenciamento de "histórias" não antes contadas. Trata-se, segundo o autor, e, se pudéssemos aproximá-lo com o pensamento de Jörn Rüsen (2001), de uma orientação prática no tempo que possui sentido de projeção, interferindo diretamente na forma e no conteúdo da consciência histórica humana que, por pressuposto, deveria ser global.

Segundo Samir Amin, o culturalismo ocidental situa a Europa como exemplo histórico que por pressuposto "deve ser imitado" no que diz respeito a sua experiência histórica e seu sentido de desenvolvimento civilizatório (AMIN, 1989, p.13). Tal perspectiva estaria intimamente ligada a um universalismo contraditório: por um lado, busca impor uma perspectiva homogênea sobre o progresso da humanidade, ao mesmo tempo que proclama um "elogio à diferença", que nada mais é que a construção de uma fragmentação insuperável e inatingível por parte daqueles que não se situam dentro do devir e do exemplo histórico do atual sistema mundial de produção, o capitalismo e sua roupagem ideológica, a "utopia liberal" .

O "universal" - que possui sua gênese no helenismo, um "Mito de Origem" - obscurece a importância do Egito para a formulação da filosofia grega, além de abandonar outras culturas civilizatórias que fazem parte do contexto e que são silenciadas em maior ou menor grau nos materiais didáticos e em nossa cultura historiográfica. Apresenta-as como fenômenos históricos desarticulados e pouco integrados ao longo do tempo. Há, nessa perspectiva narrativa, a sincronia entre o silêncio e o elogio à diferença, principalmente porque, em seu olhar, existe o abandono pelo todo, ou, dialogando com Rüsen, da visão que privilegia o olhar para as árvores em detrimento da floresta, prejudicando, inclusive, um olhar intercultural sobre a história:

O reconhecimento, desde um começo, da diversidade de culturas humanas, constitui em uma trivialidade cuja evidência dissimula a dificuldade conceitual de captar sua natureza e seu alcance. Pois onde estão as fronteiras no espaço e no tempo de uma 
cultura particular? Sobre quais fundamentos é definida sua singularidade? Por exemplo, pode-se falar hoje em dia de uma cultura europeia que abarque todo o Ocidente apesar das diferentes expressões linguísticas? Se é assim, será incluída a Europa oriental, não obstante seu regime social e político diferente, a América Latina não obstante seu subdesenvolvimento, o Japão, apesar de suas raízes históricas não europeias? Pode-se falar de uma só cultura do mundo árabe, ou árabe-islâmica, de uma só cultura da África negra, da Índia? O que deve se renunciar a essas conceituações totalizadoras e nos conformar em observar a especificidade dos subconjuntos constitutivos desses grandes conjuntos? Pois então, onde deve ser detida a engrenagem sem fim da singularidade provincial? E qual é a pertinência das diferenças observadas, sua força explicativa das evoluções sociais? (AMIN, 1989, p.23 - tradução nossa).

As perguntas do autor são importantes para compreendermos seu caminho, pautado em uma teoria da história que enxerga a evolução das civilizações a partir das relações entre centros e periferias, desenvolvendo assim a tese de que haveria sociedades tributárias e comunitárias. Ambas possuem demarcações históricas específicas no espaço-tempo.

Continuando nosso diálogo com os autores que se situam numa perspectiva crítica ao fenômeno de sentido temporal a ser estudado - o eurocentrismo - é importante apresentar as abordagens de Enrique Dussel e Aníbal Quijano. Ambos do campo decolonial. Aproveito de Dussel e suas reflexões em torno do "Mito da Modernidade". Segundo o filósofo argentino radicado no México, tal mito se materializa em torno da ideia de descobrimento. Ele inaugura e completa o estágio de autoconstrução do europeu como vanguarda da História Mundial:

\footnotetext{
'Descobrir', então - e isto acontecido histórica ou empiricamente de 1502 a 1507 - é constatar a existência de terras continentais habitadas por humanos ao oeste do Atlântico até então totalmente desconhecidas pelo europeu, o que exige 'abrir' o horizonte ontológico de compreensão do 'mundo da vida cotidiana (Lebenswelt)' europeu rumo a uma nova 'compreensão da história como acontecimento mundial [...] planetário. Isto é concluído em 1520, quando Sebastião Elcano, sobrevivente da expedição de Fernando de Magalhães, chega a Sevilha tendo descoberto o estreito de Magalhães, percorrido o Oceano Pacífico (desaparece só agora a hipótese do 'Sinus Magnus') e o Índico, e circunavegado a terra pela primeira vez. Agora o círculo se fechava: a terra tinha sido 'des-coberta' como o lugar da 'história mundial' (DUSSEL, 1993, p.26).
}

O fato de se ter entrado em contato com todos os continentes garantiu ao longo da história o sentido de vanguarda do europeu perante o restante do mundo. Por isso, é com o europeu que se inaugura, a partir de uma perspectiva de enaltecimento e imposição cultural, a dialética entre civilizados versus bárbaros/selvagens e que, na visão do autor, se perpetua a partir das relações de poder, consolidadas a partir da dialética moderna entre países europeus 
desenvolvidos e periferias subdesenvolvidas (as ex-colônias africanas, asiáticas e latinoamericanas) (DUSSEL, 1993, p. 26). Nesse sentido, não há uma teoria holística, e sim a autoreivindicação de uma parte (o europeu) em detrimento do todo (o resto da humanidade), alheia e impotente, inclusive, quanto a sua capacidade de se orientar e dar sentido cultural à experiência humana.

Para Aníbal Quijano, a conquista inaugura um novo padrão de poder no sistema-mundo a partir do século XVI. Centrado fundamentalmente em uma divisão fenotípica, as invasões espanhola e portuguesa estabelecem uma nova tradução para a divisão entre governantes e governados. Há uma linha clara de separação entre conquistadores dos povos originários e os conquistados. Tal divisão fenotípica materializaria uma das principais categorias taxonômicas eurocêntricas: a visão sobre tais povos a partir do ser índio. Ela provocaria uma homogeneidade fundamental para a imposição de um projeto de conquista, por meio da violência e a exploração:

[Os conquistadores] reprimieron tanto como pudieron, es decir en variables medidas según los casos, las formas de producción de conocimiento de los colonizados, sus patrones de producción de sentidos, su universo simbólico, sus patrones de expresión y de objetivación de la subjetividad (QUIJANO, 1993, p.126).

Afinal, esta dominação retroalimentaria a nova divisão do trabalho instituída no continente. Nesse sentido, Quijano vai um pouco mais além das definições propostas por Gunder Frank. Segundo o professor peruano, o capitalismo mundial inaugurado com a conquista promoveu uma Divisão Racial do Trabalho. Tal divisão gerou, portanto, um etnocentrismo intrínseco da colonialidade do poder. Afinal, com a divisão fenotípica instituída, haveria a promoção ideológica ocasionada pela dominação das classes dominantes - os conquistadores- de uma "sensação de superioridade natural". Nasceria, assim, na América Latina, um poder eurocentrado como paradigma gerado por meio de binarismos formulados pelo sistema de dominação cultural.

O conhecimento binário seria estabelecido de forma maniqueísta, cuja interpretação das culturas se basearia numa visão escalonada entre civilizados e primitivos. A assimilação e interpretação das culturas se daria a partir deste paradigma e, consequentemente, produziria consigo dois mitos: 1) de uma Europa como imagem a ser alcançada, em oposição aos "homens selvagens em estado de natureza"; e 2) uma distinção racial entre ser europeu e o não europeu. Ambos mitos fortaleceriam paradigmas científicos evolucionistas e dualistas (QUIJANO, 1993, 
p. 211). O campo decolonial, pode-se dizer, também possui uma matriz de pensamento oriunda da Teoria do Desenvolvimento. Tanto Enrique Dussel como Aníbal Quijano se dizem próximos às perspectivas anunciadas por Amin e Frank. Apesar disso, as relações entre o campo decolonial e os marxistas em geral têm sido marcadas por um amplo debate e divergências, devido aos elementos culturais específicos reivindicados pelo decolonialismo.

Percebe-se até o momento que as análises desses autores se diferem com relação à ótica do objeto de estudo: se por um lado temos uma preocupação telescópica-econômica de Gunder Frank e, em alguma medida, de Samir Amin - que parte das relações de produção para produzir uma crítica às perspectivas culturalistas -, Enrique Dussel e Aníbal Quijano se preocupam com a materialização da visão de mundo eurocêntrica no continente latino-americano. Mesmo que paralelamente, pode-se dizer que há uma proximidade entre os autores decoloniais e póscoloniais quanto as suas preocupações, uma vez que tentam compreender o processo de provincialização da Europa nas periferias.

\section{Considerações finais}

Os debates em torno do conceito de eurocentrismo perpassam por dimensões analíticas variadas conforme as escolas de pensamento. Como apresentado, existem interseções sobre a crítica a uma história de raiz eurocêntrica entre todas as vertentes. No entanto, cabe ressaltar suas diferenças significativas e semelhanças.

No que diz respeito à análise metodológica, as teorias do desenvolvimento e da história global/ Teorias da Dependência se assemelham quanto ao seu escopo analítico. Ambas produzem uma escrita da história mais telescópica e se identificam ao se proporem a analisar o espaço histórico por meio de grandes objetos de investigação, que trazem consigo uma análise das trocas comerciais e das simultaneidades nas relações globais de produção, impostas a partir de uma divisão internacional do trabalho.

Com relação as suas divergências, percebo uma variável geopolítica na escrita da história que fazem com que ambas assumam caminhos distintos. As arestas entre os intelectuais destas vertentes estão ligadas às concepções sobre a globalização. Se para a teoria do desenvolvimento a globalização é um processo que "existe há dois mil anos", a global history surge como uma historiografia que quer problematizar esse processo tendo como marco o início dos anos 1990. Mesmo que saiba as contradições desse processo, assumindo uma leitura 
wallersteiniana, não se pode deixar de notar que o surgimento desta vertente intelectual está ligado principalmente às crises de representação historiográfica de fins do século.

A análise que privilegia os lugares de fala e a escrita da história a partir de novas subjetividades são perceptíveis na história intelectual proposta pelos autores decoloniais e póscoloniais. Por mais que partam de pressuposições vinculadas ao pensamento de André Gunder Frank, se diferem quanto ao objeto de investigação, uma vez que procuram refletir sobre a mediação cultural da história enquanto fenômeno epistemológico e as imposições feitas em um mundo não-ocidental de conceitos e experiências que se estabelecem a partir do jogo da imposição e da realização do projeto colonial, ou, melhor dizendo, de provincialização da Europa no Terceiro Mundo. Há nessas duas vertentes, um ponto de partida telescópico. No entanto, o seu caminhar é trilhado por outros pressupostos. Arrisco dizer: mais microscópicos e, portanto, vinculados às especificidades culturais que dão a substância antieurocêntrica em seus discursos. 


\section{Referências bibliográficas:}

AMIN, Samir. El eurocentrismo. Cidade do México: Siglo Veintiuno editores, 1989.

CHAKRABARTY, Dipesh. Provincializing Europe: Postcolonial thought and Historical Difference. Princeton: Princeton University Press, 2000.

DE CERTEAU, Michel. A escrita da história. Rio de Janeiro: Forense Universitária, 1982.

DIRLIK, Arif. Is there History after Eurocentrism? Globalism, Postcolonialism, and the disavowal of History. In: Cultural Critique. Minneapolis: University of Minnesota Press, 1999, pp. 1-34, number 42 .

DUSSEL, Enrique. O Encobrimento do Outro (a origem do "mito da modernidade"). Petrópolis: Vozes, 1993.

FRANK, Andre Gunder. Reorient: global economy in the Asian Age. Berkeley \& Los Angeles: University of California Press, 1998.

HOBSBAWM, Eric. The Age of Extremes: The Short Twentieth Century: 1914-1991. London: Abacus, 1994.

MARX, Karl. Acerca del Colonialismo. Moscou: Editorial Progreso, 1981.

OURIQUES, Nildo. O colapso do figurino francês: Crítica às ciências sociais no Brasil. Florianópolis: Editora Insular, $3^{\mathrm{a}} \mathrm{ed}, 2015$.

PACHECO, Perla. Hacia uma nueva historia global no eurocêntrica: um balance crítico, Transhumante. Revista Americana de Historia Social 9, p.144-165, 2017.

QUIJANO, Aníbal. Colonialidad del poder, Eurocentrismo y América Latina. In: LANGDER, Edgardo (org.). La colonialidad del saber: eurocentrismo y ciencias sociales. Perspectivas latino-americanas. Buenos Aires: CLACSO, 1993, p.122-151.

RAMOS, Jorge Abelardo. Historia de la nación latino-americana. Buenos Aires: Continente, 2012, $3^{\text {a }}$ Edição.

RIBEIRO, Darcy. O processo Civilizatório: estudos de antropologia da civilização. Petrópolis: Vozes, $5^{\text {a }}$ Ed., 1979.

RIBEIRO, Darcy. As Américas e a civilização. Rio de Janeiro: Civilização Brasileira, 1970.

RÜSEN, Jörn. Razão Histórica: teoria da história: fundamentos da ciência histórica. Brasília: UnB, 2001. 
SETH, Sanjay. Razão ou Raciocínio? Clio ou Shiva?. Ouro Preto: Revista de História da Historiografia, $\mathrm{n}^{\circ} 11,2013$, p.173-189.

VASCONCELLOS, Gilberto Felisberto. Gunder Frank: o enguiço das ciências sociais. Florianópolis: Editora Insular, 2014.

YOUNG, Robert. Postcolonialism: an historical introduction. Oxford: Blackwell Publishing, 2001. 